\title{
Raising Energy Efficiency of High-Head Drinking Water Pumping Schemes in Hilly India - Massive Potential, Complex Challenges
}

\author{
Thomas J. Voltz ${ }^{* 1}$, Thomas Grischek ${ }^{1}$, \\ Marcel Spitzner ${ }^{2}$, Jana Kemnitz ${ }^{2}$, Rudolf Irmscher ${ }^{3}$ \\ ${ }^{1}$ Division of Water Sciences, University of Applied Sciences (HTW) Dresden, Germany \\ *e-mail: voltz@htw-dresden.de \\ ${ }^{2}$ Faculty of Electrical Engineering, University of Applied Sciences (HTW) Dresden, Germany \\ ${ }^{3}$ Executive Management, Stadtwerke Heidelberg GmbH, Heidelberg, Germany
}

Cite as: Voltz, T. J., Grischek, T., Spitzner, M., Kemnitz, J., Irmscher, R., Raising Energy Efficiency of High-head

Drinking Water Pumping Schemes in Hilly India - Massive Potential, Complex Challenges, J. sustain. dev. energy water environ. syst., 2(2), pp 118-126, 2014, DOI: http://dx.doi.org/10.13044/j.sdewes.2014.02.0011

\begin{abstract}
Investigations of energy efficiency of 25 pumps showed wire-to-water efficiencies ranging from $30 \%$ to $60 \%$, with an average of $47 \%$. Raising the efficiency of just 7 pumps to the realistic target of $60 \%$ would require an initial investment of $126 \mathrm{k} €$ and represent a net present value (profit) of $446 \mathrm{k} €$ over a 10 -year pump lifetime, saving $8.6 \mathrm{kt}$ of $\mathrm{CO}_{2}$ emissions. The primary measures for raising efficiency are in order of priority: 1) improving pre-filtration of raw water to prevent rapid mechanical wear due to suspended particles during monsoon, 2) providing training, improved working conditions, and better tools and spare parts among pump operators and 3) replacing aging, oversized pumps with properly sized pumps operating close to peak efficiency. As of January 2014 the results have been confirmed by a Bureau of Energy Efficiency-certified energy auditor and the extent and funding of efficiency measures implementation is in planning.
\end{abstract}

\section{KEYWORDS}

Energy efficiency, Pumps, Drinking water, India, Capacity building, Emission reduction

\section{INTRODUCTION}

Pumps make up 20\% of the global electrical energy demand, and 60 to $95 \%$ of that of drinking water supply systems [1-3]. This use of energy represents 70 to $90 \%$ of the life cycle cost of a pump, depending on the required head and flow as well as cost of maintenance and personnel [4-6]. By comparison, the up-front purchase cost of a new pump tends to lie between 3 and $10 \%$ of its life cycle costs [7]. This underlines the importance of stressing high energy efficiency in the selection of a pump, which ought to be the second priority after meeting the drinking water demand. Pumping systems are known to have a significant potential for energy efficiency improvements [8-12]. This is primarily because it is rather easy to select and operate pumps at low efficiency through conservative over dimensioning, changing demand requirements, inefficient flow control (bypass or throttle rather than variable speed operation) [13, 14], inefficient pump scheduling [15] and negligent or poor maintenance [16]. The energy and cost savings that stand to be gained through modification or replacement pumping systems are estimated to be as high as $30 \%$ [8].

\footnotetext{
* Corresponding author
} 
Although according to the literature cited, this topic is well known and well researched in Europe and North America, in India this appears not to be the case, despite what is likely a large potential. Attention has been given to irrigation pumping systems and their energy efficiency $[17,18]$, but scientific studies specifically on drinking water pumping systems are scarce. Past experiences in India [19] and elsewhere have also shown that many projects fail to succeed due to problems with an agreeable funding solution and effective execution by a team composed of private consultants and public water supply company engineers. This paper will analyse the example of the drinking water supply pump systems of the hill cities of Srinagar/Pauri and Mussoorie in Uttarakhand, India. The goal is to illustrate 1) the current state of energy efficiency, 2) the reasons for low efficiency and the corresponding approaches to improving it and 3 ) the potential for energy and cost savings and thoughts on how to best achieve them.

\section{DRINKING WATER SUPPLY IN UTTARAKHAND, INDIA}

In the hill regions of the small North-Indian state of Uttarakhand (Lower and Middle Himalaya), drinking water supply is almost exclusively based on surface water. Most schemes for small villages are gravity-fed, but approximately 30 large towns $(>5,000$ inhabitants) require additional input of energy via electric motor-driven pumps to lift the water to the point of consumption. At the two study areas Srinagar/Pauri and Mussoorie horizontal multistage centrifugal pumps are used to lift water as much as 1,700 $\mathrm{m}$ from rivers and streams to storage tanks, requiring multiple boosting stations and working heads up to $600 \mathrm{~m}$ for moderate flows up to $120 \mathrm{~m}^{3} / \mathrm{h}$. As individual pump-motor sets have real power demands as high as $200 \mathrm{~kW}$, pumping is very energy intensive and comprises $>90 \%$ of the electricity demand. The partner water supply organization Uttarakhand Jal Sansthan (UJS) pays app. 1 million $€ /$ year in electrical energy bills for pumping at these two areas alone.

Figures 1 and 2 show the central raw water extraction station for the hill city Srinagar, through which 70,000 people are supplied with approximately $10,000 \mathrm{~m}^{3} /$ day of drinking water. The existing pump sets are exposed to the damaging effects of nature, chief among them the annually recurring monsoon with high-turbidity floods of varying intensities. The potential for improvement is evident.

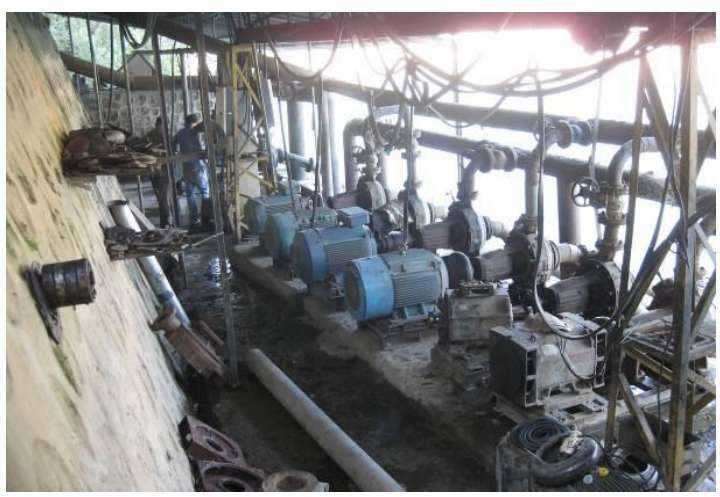

Figure 1. Single-stage raw water pumps installed on an open platform in Srinagar

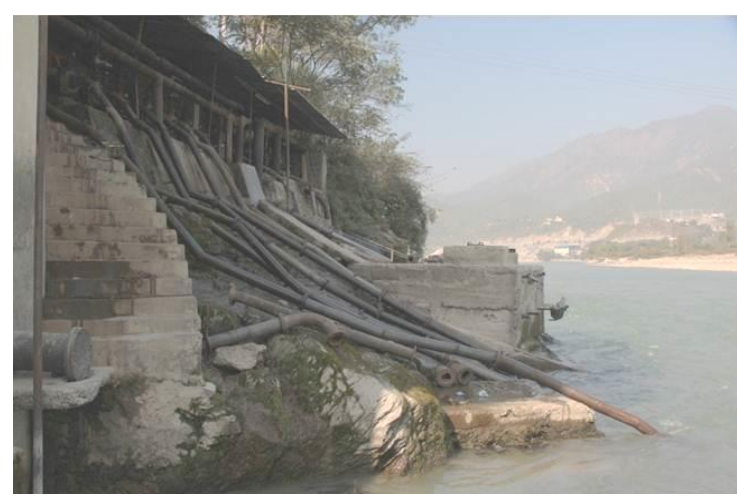

Figure 2. Suction pipes with non-return valves in the River Alaknanda

At the second study area in the hill city of Mussoorie, staff and students of the University of Applied Sciences Dresden, supported by the contracted Indian certified energy auditor, inspected 45 multistage pumps, of which 25 were in operating condition. Measurements of flow, pressure rise across the pump (difference between discharge and 
suction pressures) and electrical power input yielded a mean "wire-to-water" energy efficiency of $47 \%$, with values ranging from 30 to $60 \%$. Of the 22 pumps, 10 were over dimensioned by a margin greater than $15 \%$, meaning the rated head (as on the nameplate) was $15 \%$ greater than the actual working head measured during operation using an analog pressure gauge. The appearance of the pump and pump house was often an unreliable indicator of efficiency (Figure 3), such that examples of relatively efficient pumps were also found in unexpected places (Figure 4).

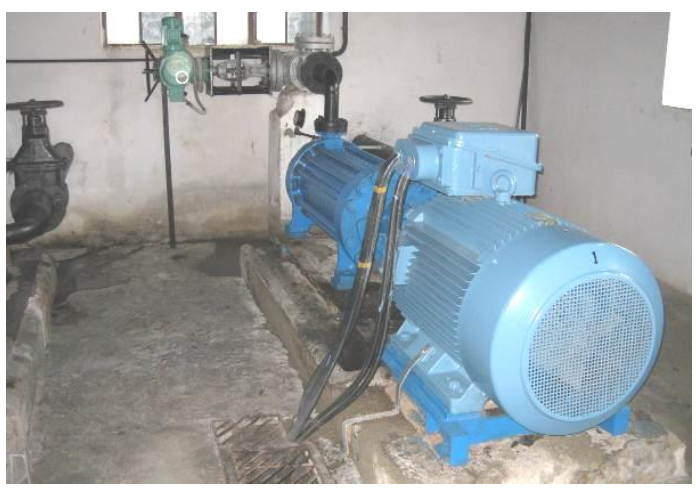

Figure 3. Pump set 1 at Jinsy II Pump Station, wire-to-water efficiency of $47 \%$, Mussoorie

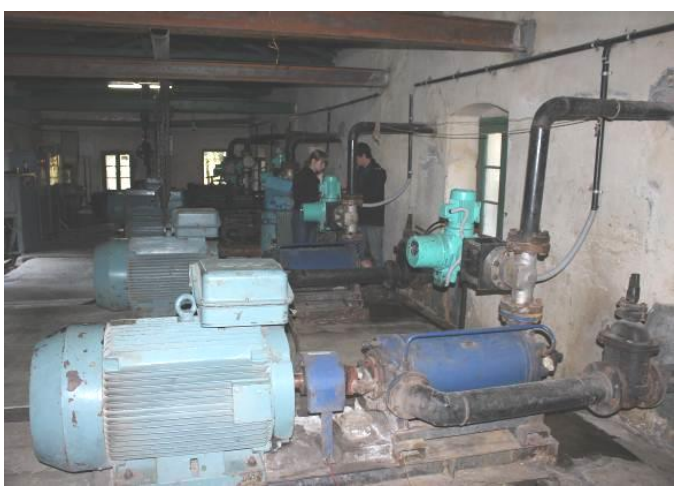

Figure 4. Pump set 6 at Murray Pump Station, with an efficiency of nearly $60 \%$

\section{MEASURES FOR AND CHALLENGES AGAINST RAISING EFFICIENCY}

Experience gained during measurements has revealed three primary measures necessary for raising the efficiency and the salient challenges that must be overcome to implement these measures.

\section{Pre-treatment}

In many cases there is inefficient or non-existent raw water pre-treatment through physical filtration to remove suspended particles (silt and sand). This problem is especially severe during monsoon. The internal components of the pumps, which due to high head requirements operate predominantly at rotational speeds of $3,000 \mathrm{~min}^{-1}$, are heavily eroded and rapidly lose efficiency. For example, the raw water pumps in Figure 1 are normally replaced or completely overhauled every year after monsoon. After replacement, they have a total efficiency of $60 \%$, but after one year drop to an average of about $30 \%$. This fact is well known among UJS engineers and explains the ubiquitous over dimensioning, since the pumps would otherwise be unable to meet their operating requirements after just a few years, as has been the case several times in the past. Many "clear water" pumps at sites in Mussoorie are also likely affected, which due to their high energy consumption compared to the raw water pumps is even more costly. This problem can be addressed by superior intake structures (Srinagar) or improved filtration and sedimentation (Mussoorie) before the pump inlets as well as erosion-resistant impeller materials and surface coatings.

The main challenge against improving this pre-filtration is designing for the extreme flow and high shear stress conditions that develop during monsoon, which require structures with well-anchored foundations and a robust superstructure. This requires a complex engineering solution and large initial investments, which according to UJS engineers are very difficult to obtain. This is due to a culture of short-term planning and brought about to a large extent by the difficult climatic conditions, which cause extensive 
damage to water supply schemes each year and keep the focus on the many recurring repairs, rather than allowing for carefully planned schemes with longer lifetimes and higher initial investment requirements.

\section{Training and equipment of pump operators}

Most pump operators possess a low level of training and rely solely on practical experiences gained on the job. Their operation and maintenance methods often achieve baseline effectiveness, but far from the technical standards common for example in Europe. The working conditions with respect to safety (risk of falls, noise level, room lighting) are generally in need of improvement. Special tools are rarely available, such that complex tasks such as exact alignment of the pump and motor cannot be correctly executed. High-quality spare parts such as pump bearings and impellers are more expensive and difficult to obtain, such that lower-quality and less-expensive local options offer the only feasible solutions to urgent repair needs. These problems can best be addressed through intensive and regular training programs for the pump operating staff with focus on pump installation and maintenance. This must be accompanied by an improvement in the pump station working conditions and availability of appropriate tools and selected spare replacement parts. In this way, higher energy efficiency would be a positive side-effect.

Challenges to this include the general opinion that investments in the training of low-level workers are not very beneficial, and difficulty in overcoming the institutional inertia to change the status quo. In some cases, such as in Srinagar, the pump staff are outsourced from other companies and employed on short-term contracts, a fact which speaks against investing in their education. In India it is common for lower-level employees to display limited loyalty to their companies and to seek and pursue the best economic opportunity available.

\section{Systematic pump replacement}

Once the first measures have been implemented, the pumps should be systematically replaced, beginning with the oldest, least efficient pumps with the highest electric power consumption and operating hours. The selection of new pumps must be done properly to avoid unnecessary over dimensioning. Similarly, the operating regime must be taken into account in the pump controls, for example such that in the case of widely varying pump duty requirements the efficiency is kept at a maximum. This can be accomplished for example by a variable frequency drive in place of a typical throttle valve, or an effective parallel operation of one high-flow and one low-flow pump in place of two identical pumps.

Other technical measures identified by the certified energy auditor [20] also show promise, such as compensating for low power factors using capacitor banks, adjusting the contracted maximum electrical load (in $\mathrm{kW}$ ), and drawing power at higher voltage. These proposed measures will be included in the planning for the implementation of energy efficiency improvement measures in 2014.

\section{POTENTIAL FOR COST SAVINGS AND CO $\mathrm{CO}_{2}$ EMISSION REDUCTION}

\section{Pump replacement vs. continued operation of existing pumps}

To illustrate the savings potential for all 25 pumps measured in Mussoorie, a conservative cost-benefit analysis was conducted using a dynamic cost comparison. In the improved case, it was assumed that all pumps were replaced with new pumps from the German manufacturer KSB (also widely available in India), which were chosen using 
their proprietary internet-based tool "KSB EasySelect" according to the operating requirements measured with open throttle valve. The pump lifetime (running time without complete replacement or major repair) was set to a maximum of 20 years and a specific price per capacity $(€ /[\mathrm{m} \times 1 / \mathrm{min}])$ for purchase, installation and of the new pump, which varied as a falling power function. The means that the specific price decreases according to the following function:

$$
\text { Specific Costs in Rs. }(\text { INR })=17.07 \times(\text { Head } \times \text { Flow })^{-0.4508}
$$

This was based on recent price quotes for 7 pumps received from UJS. As an example, a pump with a required flow of 1,200 1/min and a head of $315 \mathrm{~m}$ would have a specific investment cost of $0.0522 € /(\mathrm{m} \times 1 / \mathrm{min})$ and incur a total investment cost of $19,750 €$. It was assumed that the efficiency of the new pumps would linearly degrade throughout their lifetime, such that in the final year of operation they reach the current efficiency of the pump to be replaced. The initial electricity price was $5.4 \mathrm{ct} € / \mathrm{kWh}$ with a rapid price increase of 13.3\%/year (based on pump station electricity bills from 2010 to 2013). A nominal interest rate of $7.75 \%$ was used (based on World Bank data). In the base case, it was assumed that the all pumps would continue to be operated with an unchanging efficiency. These two cases were compared based on their net present values.

Figure 5 shows the progression of the net present values for each pump with respect to pump lifetime, calculated by subtracting the net present value of the base case from that of the improved case. The exponentially rising curves show the influence of the very high electricity price increase and make it clear that a long lifetime (for example through improved maintenance) can yield especially large cost savings. The replacement of 7 pumps (black solid lines) leads to particularly good economic viability owing to their high operating hours and electrical power consumption, and results in payback periods (intersection of the net present value lines with the x-axis) from 4.5 years to 1 year. Only 4 of 25 the replacements do not pay for themselves within the simulated maximum 20-year pump lifetime.
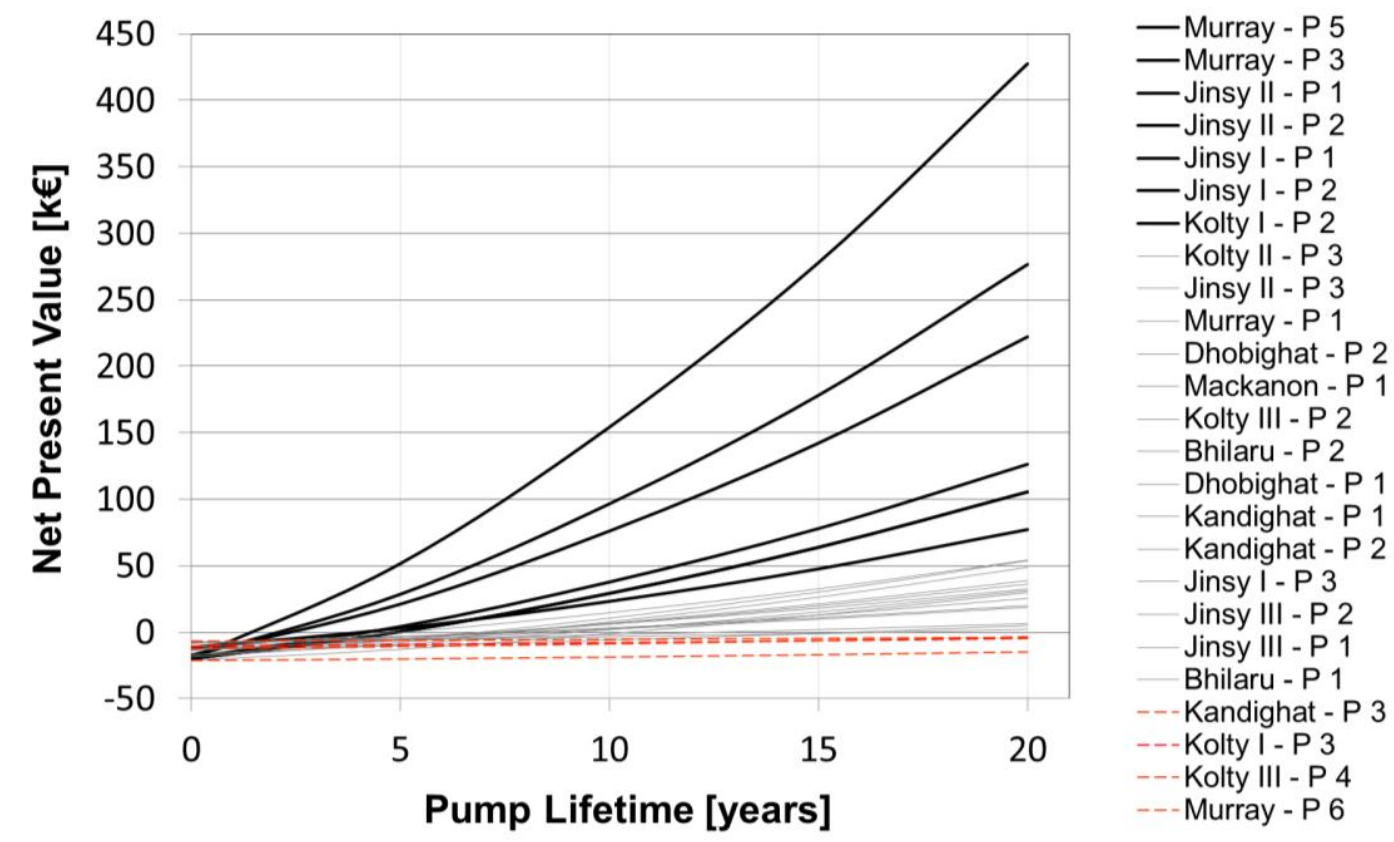

Figure 5. Economic viability of the replacement of the existing 22 pumps in Mussoorie with new pumps, as shown by the difference in net present value between pump replacement (improved case) and continued operation of existing pumps (base case). $\mathrm{k} €=$ thousand Euro 


\section{Emission reduction}

Improvements in pumping energy efficiency can yield not only large cost savings, but also substantial $\mathrm{CO}_{2}$ emissions reduction from imported electricity from outside the state of Uttarakhand, of which 67\% is generated using fossil fuels (Figure 6). Based on figures from the Central Electricity Authority [24] for tons of $\mathrm{CO}_{2}$ output per MWh of coal (1.08 $\mathrm{t} / \mathrm{MWh})$ and gas $(0.46 \mathrm{t} / \mathrm{MWh})$ burned in North Indian power plants, and the mixture of imported fossil-based electricity into Uttarakhand (55\% coal, $12 \%$ gas), the conversion factor is $0.968 \mathrm{t} / \mathrm{MWh}$. This assumes that only fossil-based electricity is replaced by energy efficiency improvements, as per a federal policy that favours the generation from other sources such as hydropower.
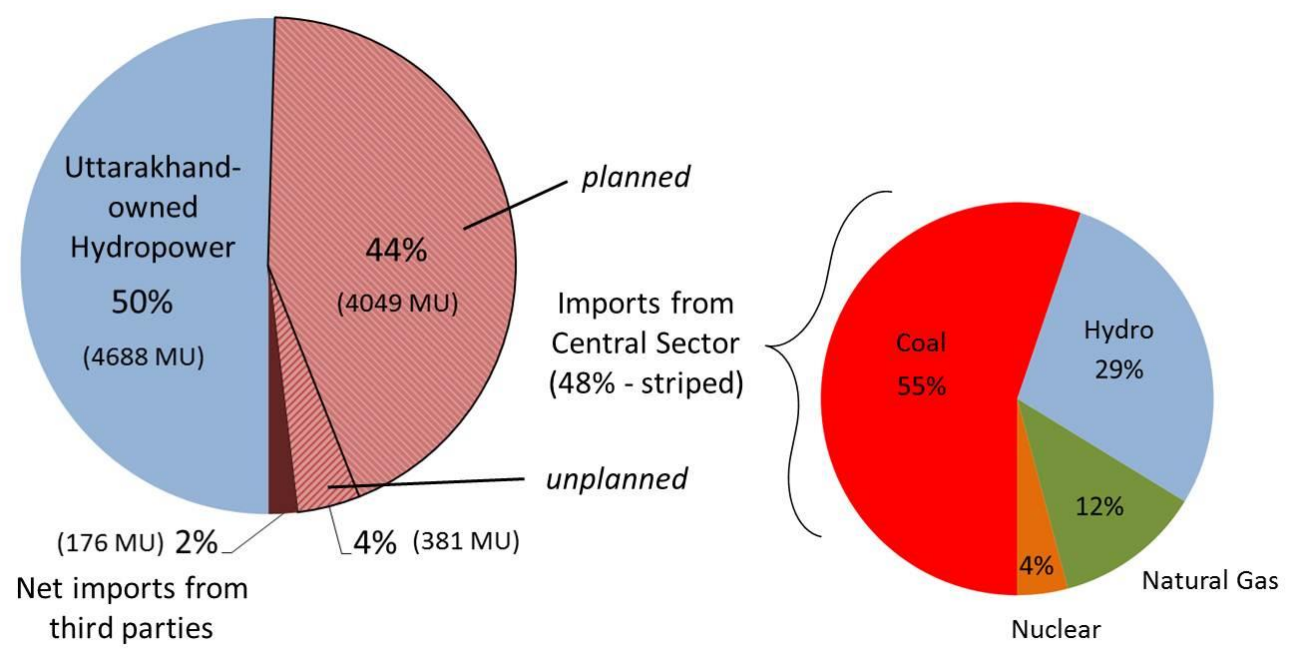

Figure 6. Electrical energy quantities generated in Uttarakhand, 2010-11, broken down according to fuel type and source of supply, whether in-state or from neighboring states (central sector). MU (Million Units) $=$ GWh [21-23]

\section{Total savings}

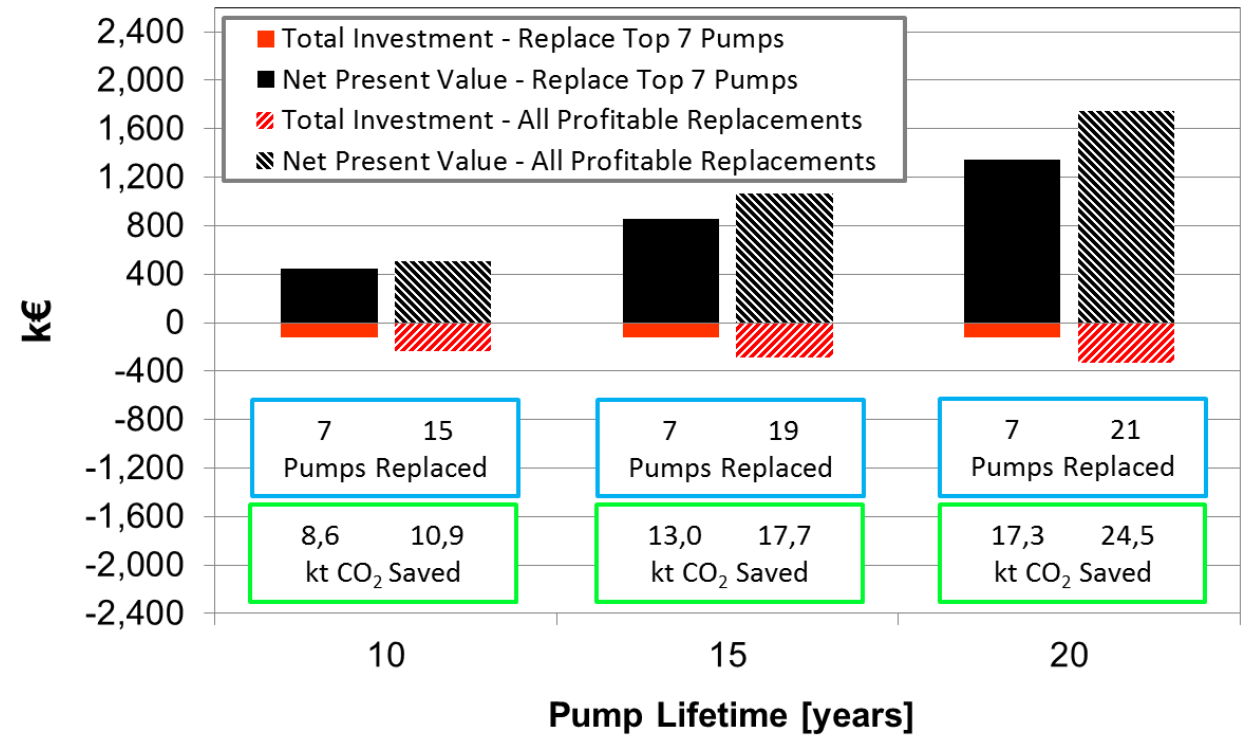

Figure 7. Net present values and total investment costs for pump replacement under various assumptions of the lifetime for 7 pumps and all pumps, respectively, for Mussoorie. $\mathrm{k} €=$ thousand Euro, $\mathrm{kt}=$ thousand tons 
The cost savings and $\mathrm{CO}_{2}$ emission reduction possible through the replacement of just 7 pumps are shown in Figure 7 for three different pump lifetimes. The investment of funds should always be made for those pumps, which yield the greatest returns. For example, the investment of $126 \mathrm{k} €(\mathrm{k} €=$ thousand Euro) for the replacement of 7 pumps leads to a savings (profit) of $446 \mathrm{k} €$ after a 10 -year lifetime versus continued operation (base case), a rate of return of $353 \%$. This results in a $\mathrm{CO}_{2}$ emission reduction of $8.6 \mathrm{kt}$ ( $\mathrm{kt}=$ thousand tons). By contrast, a nearly twofold investment of $241 \mathrm{k} €$ for the replacement of 17 pumps after a 10-year lifetime yields a savings of $507 \mathrm{k} €$ and a rate of return of (only) $210 \%$.

\section{CONCLUSION AND THOUGHTS ON FINANCING THE IMPLEMENTATION}

The authors recommend that UJS undertake a pilot energy efficiency project to replace some or all of the 7 pumps in Mussoorie showing the greatest potential savings. The number to be replaced depends on the amount of funding that can be acquired externally or freed up internally by UJS to cover initial investment costs. Based on discussions and experiences thus far, external funding will be necessary, and is in the process of being applied for with the aid of a state-level funding agency (Uttarakhand Renewable Energy Development Agency, UREDA), once these first measurements of energy efficiency are confirmed by an accredited energy auditor. As UJS has limited additional engineering capacity to oversee the technical implementation of this project, which is of secondary importance compared to effective water supply, continued support from a third-party will be required.

In the best case this would be done by an energy service company (ESCO) that provides investment funding and engineering services and later receives payment on the basis of performance contracting. This means that the ESCO receives its payment as a percentage of the cost savings achieved each year for a contractually agreed-upon period following the implementation of the efficiency measures. While such companies are active in North India, they are more hesitant to enter into such contracts with municipal organizations, which face various challenges that could affect regular payments. For this, a second third-party company or bank may be required to broker the payments via a special account.

UREDA itself could act as a kind of non-profit ESCO by providing a small amount of funding as an interest-free loan, which could suffice for the replacement of 2 or 3 pumps. Alternatively, although less desirable in the eyes of the authors, is the possibility of receiving a low-interest loan from the Indian Renewable Energy Development Agency (IREDA), which carries a grace period up to 3 years before repayment begins. This should allow for sufficient time to reap the benefits of the improved efficiency and enable timely repayment without additional financial burden on the UJS budget. However, in both cases an external engineering firm in India will need to be separately arranged to supervise the implementation. These options will be explored in the coming months such that implementation of at least pilot-scale measures can be achieved by the end of 2014 .

\section{ACKNOWLEDGEMENTS}

The encouragement and organisational support of Mr. A.K. Tyagi of UREDA, the technical support of the staff of UJS, especially Mr. P.C. Kimothi, Mr. L.K. Adlakha, Mr. S.K. Sharma and Mr. Rohela, the electro technical consultation of Mr. S. Dhamija of Simplex Control Systems Co., and the advice and field work of Mr. Rakesh Yecho of Technical \& Management Consultancy Center (subcontractor of PCRA) and his team are gratefully acknowledged. Funding of the project was provided by the Stadtwerke 
Heidelberg $\mathrm{GmbH}$ in agreement with the certification agency GSL (Green Electricity Label). Additional support was received through the DAAD programme "A new passage to India 2013-2014" (grant no. 56040107).

\section{REFERENCES}

1. Europump and Hydraulic Institute, Pump Life Cycle Costs: A Guide to LCC Analysis for Pumping Systems, $1^{\text {st }}$ Edition, Ed. Lars Frenning. Parsippany, New Jersey, 2001.

2. Schweizericher Verein des Gas - und Wasserfaches (SVGW) und EnergieSchweiz, Energy in the water supply - Guide to energy cost and operational optimization, Zürich, 2004. (in German)

3. de Almeida, A., Fonseca, P., Falkner, H., Bertoldi, P., Market transformation of energy-efficient motor technologies in the EU, Energy Policy, 31(6), pp. 563-575, 2003, http://dx.doi.org/10.1016/S0301-4215(02)00100-3

4. Electric Power Research Institute (E PRI), Program on Technology Innovation: Electric Efficiency through Water Supply - A Roadmap, Palo Alto, California, USA, 2009.

5. Deutsche Energie-Agentur GmbH (DENA), Pumps and pump systems gudie for industry and commerce, Pumps and pump systems guides for industry and commerce, Initative EnergieEffizienz, Berlin, 2010. (in German)

6. Global Water Research Coalition (GWRC), Energy Efficiency in the Water Industry: A Compendium of Best Practices and Case Studies - Global Report, International Water Association (IWA) Publishing, London and New York, 2012.

7. Dickenson, T. C., Pumping Manual, Oxford, UK: Elsevier Advanced Technology, 1995.

8. Kaya, D., Yagmur, E. A., Yigit, K. S., Kilic, F. C., Eren, A. S. and Celik, C., Energy efficiency in pumps, Energy Convers Manag, 49(6), pp. 1662-73, 2008, http://dx.doi.org/10.1016/j.enconman.2007.11.010

9. Ferreira, F. J. T. E., Fong, C., and de Almeida, T., Ecoanalysis of variable-speed drives for flow regulation in pumping systems. IEEE Transactions on Industrial Electronics, 58(6), pp. 2117-2125, 2011, http://dx.doi.org/10.1109/TIE.2010.2057232

10.Pemberton, M., and Bachmann, J., Pump systems performance impacts multiple bottom lines, Engineering \& Mining Journal, 211(3), pp. 56-59, 2010.

11.Zhang, H., Xia, X., and Zhang, J., Optimal sizing and operation of pumping systems to achieve energy efficiency and load shifting, Electric Power Systems Research, 86, pp. 41-50, 2012, http://dx.doi.org/10.1016/j.epsr.2011.12.002

12.Vilanova, M. R. N. and Balestieri, J. A. P., Energy and hydraulic efficiency in conventional water supply systems, Renew Sustain Energy Rev, 30, pp. 701-714, 2014, http://dx.doi.org/10.1016/j.rser.2013.11.024

13.Europump and Hydraulic Institute, Variable Speed Pumping: A Guide to Successful Applications, $1^{\text {st }}$ Edition, Cornwall, Great Britain, 2004.

14.Viholainen, J., Tamminen, J., Ahonen, T., Ahola, J., Vakkilainen, E., Soukka, R., Energy-efficient control strategy for variable speed-driven parallel pumping systems, Energy Efficiency, 6(3), pp. 495-509, 2013, http://dx.doi.org/10.1007/s12053-012-9188-0

15.Bagirov, A. M., Barton, A. F., Mala-Jetmarova, H., Al Nuaimat, A., Ahmed S. T., Sultanova, N., Yearwood, J., An algorithm for minimization of pumping costs in water distribution systems using a novel approach to pump scheduling, Mathematical and $\begin{array}{lllll}\text { Computer } \quad \text { Modelling, } & \text { 57, }\end{array}$ http://dx.doi.org/10.1016/j.mcm.2012.09.015

16.Feldman, M., Aspects of energy efficiency in water supply systems, Proceedings of the $5^{\text {th }}$ IWA Water Loss Reduction Specialist Conference, South Africa, 2009.

17.Purohit P. and Kandpal, C., Renewable energy technologies for irrigation water pumping in India: projected levels of dissemination, energy delivery and investment requirements 
using available diffusion models, Renew Sustain Energy Rev, 9(6), pp. 592-607, 2005, http://dx.doi.org/10.1016/j.rser.2004.07.002

18.Shah, T., Scott, C., Kishore, A., Sharma, A., Energy-Irrigation Nexus in South Asia: Improving Groundwater Conservation and Power Sector Viability, Second (Revised) Edition, International Water Management Institute, Colombo, Sri Lanka, 2004.

19.Bureau of Energy Efficiency (BEE), Alliance to Save Energy \& International Finance Corporation (IFC), INDIA: Manual for the Development of Municipal Energy Efficiency Projects, Copyright 2007 by IFC, New Delhi, 2008.

20.Petroleum Conservation Research Association (PCRA), Energy Audits of Drinking Water Pumping Stations in Uttarakhand, June/November 2013, on Behalf of the Uttarakhand Renewable Energy Development Agency (UREDA), January 2014, Delhi.

21.Central Electricity Authority (CEA), Operation Performance of Generating Stations in the Country during the Year 2010-11, Operating Performance Monitoring Division, April 2011, Delhi, 2011.

22.Northern Regional Load Despatch Center (NRLDC), Daily Power System Energy Reports, April 2010 to March 2011, Power System Operation Corporation Limited, Delhi, 2011a.

23.Northern Regional Load Despatch Center (NRLDC), Annual Report 2010-11, Power System Operation Corporation Limited, Delhi, 2011b.

Central Electricity Authority (CEA), $\mathrm{CO}_{2}$ Baseline Database for the Indian Power Sector, User Guide. November 2006, Delhi, http://www.cea.nic.in /reports/planning/-cdm_co2/final_user_guide.pdf, [Accessed: 04-Jun-2012] 